\title{
Recovery from dementia: An interesting case
}

David Knopman, MD, and Janet Jankowiak, MD

When people hear the word "dementia" they may think of Alzheimer disease (AD). While Alzheimer dementia is the most common type of dementia, it is not the only type. In general, dementia is a decline in thinking that most often includes problems with memory (see About Dementia). Most dementias come on slowly and worsen steadily. When someone gets the diagnosis of dementia, a cure is only very rarely possible (see p2 About Reversible Dementias).

In the current issue of Neurology, Sacks and Shulman ${ }^{1}$ report one of these rare cases of a reversal of dementia involving a patient on steroid medication. They describe a man with a painful muscle condition who was being treated with the corticosteroid drug, prednisone (a powerful medication used especially to decrease inflammation). His problems began with a change in his behavior and memory while he was traveling. He was admitted to a local hospital where he was described as "grandiose and disinhibited." When he admitted that he had been purposely overdosing himself on his prednisone, his physicians put him back on the low dose originally intended. But, he remained confused and did not return to his former self. Several months later, the man had a thorough evaluation for persistent problems with his thinking. That evaluation led to the conclusion that he had a dementia due to a degenerative disease, perhaps AD. It was thought that the high-dose prednisone might have unmasked the $A D$ and hastened its appearance. He continued to worsen over the next several months. Then, a new neurologist recommended that the prednisone be stopped completely. At that point the man began to improve dramatically.

It is well known that high-dose corticosteroids, like prednisone, can cause agitation or even a manic state. ${ }^{2}$ In this man's case, even the low-dose therapy seemed to be bothering his thinking. Previous experience with the effect of prednisone on thinking showed that when the drug is stopped, there may be a lag period of months before improvement occurs. For this man, it was not until the prednisone was stopped completely that his recovery began.

The message that Sacks and Shulman wanted to convey to neurologists was that even low doses of prednisone can cause confusion. A careful reader might question the certainty that it was the prednisone that caused this man's problem. There was no blood test or brain scan that proved that the prednisone was responsible. The case for blaming prednisone was based on the very high doses he received. Also, the parallels in time between when he received prednisone and when he was ill pointed to the prednisone as the cause of his confusion. To a neurologist, however, there may be other explanations for this man's illness. Perhaps he had a brain infection or some other acute neurological disorder that wasn't detected when he was first diagnosed. In this case, his delayed recovery just happened to coincide with stopping the prednisone. Or possibly, there were two problems. First, the overdosage of prednisone occurred.
Then, second, side effects of the medications that were started to treat his behavior appeared and led to his prolonged difficulties. For example, it is well known that risperidone (which is used to treat psychotic behavior) can cause stiffness and slowing down. Then, valproic acid (which may be used as a mood stabilizer) can make a person drowsy and confused if the dose is too high. So, was it the prednisone or not? We will never know for certain what really caused his condition.

For the 7 or 8 months of his confusional state, it was obviously miserable for him and his family. Fortunately, there was a happy ending. What are the lessons to be learned? The physicians who initially evaluated the man performed the proper set of tests, but they followed conventional wisdom that low doses of prednisone do not cause problems with thinking. Perhaps, as Sacks and Shulman suggest, that view needs to be reconsidered. But, equally important, how could this man have taken five times the prescribed dose for some extended period of time without someone like his pharmacist or physician recognizing it? Patients who adjust their own medications without talking to their doctor run a big risk of illness due to the medication itself (or not getting the desired effect if they decrease the drug on their own). This is really a key message in this whole story. Changes in thinking and behavior, especially when relatively sudden, must always be explored; they may be reversible. 


\section{What is dementia?}

Dementia is the loss of mental abilities over a period of time. People with dementia may be confused and not able to remember things. They may have difficulty especially learning new things or remembering names of people they have just met. They may get lost in places that were previously very familiar. They may have difficulty finding words. Usually these problems come on gradually and are often missed early on by family and friends. Eventually they may have problems performing normal daily activities because they lose skills they once had. Their behavior may also change; they may become suspicious or irritable when they can't do a task.

\section{What is delirium?}

In contrast to dementia, sometimes people rapidly develop confusion and changes in thinking. Neurologists use the term "delirium" for this condition that is often reversible. The typical symptoms of delirium and dementia overlap quite a bit, but can usually be distinguished over time. Often the cause of delirium can be found and treated.

\section{Is dementia reversible?}

Discovery of a reversible condition in someone with dementia is rather uncommon in usual practice. ${ }^{3}$ In the case reported by Sacks and Shulman ${ }^{1}$ in this issue of Neurology, a man became confused when on a high dose of the corticosteroid, prednisone. After he failed to improve when the dose was lowered, it was presumed that he had an underlying dementia. This man's case is being reported precisely because his delayed improvement was so unusual.

\section{Can other medications affect thinking?}

There are many medications besides prednisone that can affect thinking and memory. Medications for pain, sleep, and anxiety, for example, can all easily make a person slow down mentally. For this reason there are usually warning labels against driving or using dangerous equipment. Heart medication such as digitalis or propranolol, and medications to treat seizures and depression, also can affect thinking. To be sure, these medications usually do not cause confusion when taken at the proper dose. Because every person is unique, it isn't always possible to know the right dose initially. Also, in older people, drugs are processed more slowly in the body and so a much lower dose may be needed.

\section{What else can mimic dementia?}

There are other psychiatric, medical and neurological conditions that may mimic dementia. Depression is a condition that is frequently accompanied by poor concentration, poor attention span, and poor memory. People with depression will often complain constantly about their memory and also about feeling sad, blue, or "down in the dumps." However, on occasion, some people who are depressed become so apathetic that they stop complaining about the depression and might be falsely labeled as demented. It is important to recognize depression because it can be treated successfully.

A wide variety of altered levels of blood chemistry, hormones, or nutrients can cause dementia. These include altered blood count and poor kidney or liver function. Major declines in levels of thyroid hormone or vitamin B12 in the blood can also cause dementia. These are all easy to diagnose with inexpensive blood tests and can be treated.

A condition known as normal pressure hydrocephalus can also mimic dementia. Normal pressure hydrocephalus is a rare but treatable condition that produces a distinctive problem in walking, poor bladder control, and dementia. A head CT or MR scan shows ballooning of the brain ventricles (the fluidfilled inner cavities of the brain) out of proportion to the apparent shrinkage of the brain itself. In appropriate patients, a tube can be placed surgically inside the brain ventricles to drain excess cerebro- spinal fluid. If the surgery is done early enough many of the problems of walking, bladder control and thinking can be reversed.

The result of a head injury, even relatively mild, can mimic dementia. A fall or bumping the head may cause blood clots to form between the inner side of the skull and the brain (called a subdural hematoma). In older people, the injury can be quite modest and even forgotten. Removal of the subdural hematoma by surgery can cure the symptoms of memory loss. Subdural hematomas can be diagnosed with certainty only with CT scans or MR scans, which is why the American Academy of Neurology recommends that all patients with suspected dementia have one of these brain scans at the time of the initial evaluation by a doctor. ${ }^{4}$

So, when a person develops confusion, especially if the symptoms come on over a short period of time (that is, days or weeks), family and physicians must consider the various possible causes for the problem. Part of the evaluation involves laboratory tests, but one critical part is finding out about all medications and all health problems that the person has. Often, the solution will appear after a careful retelling and analysis of the onset and progression of the problems.

\section{For more information}

American Academy of Neurology Foundation

www.thebrainmatters.org

Alzheimer's Association www.alz.org

\section{References}

1. Sacks O, Shulman M. Steroid dementia: an overlooked diagnosis? Neurology 2004;64 707-709.

2. Wolkowitz OM, Reus VI, Canick J, Levin B, Lupien S. Glucocorticoid medication, memory and steroid psychosis in medical illness. Ann N Y Acad Sci 1997;823:81-96.

3. Clarfield AM. The decreasing prevalence of reversible dementias: an updated metaanalysis. Arch Intern Med 2003;163:22192229 .

4. Knopman DS, DeKosky ST, Cummings JL, et al. Practice parameter: diagnosis of dementia (an evidence-based review). Neurology 2001;56:1143-1153. 


\title{
Neurology
}

\author{
Recovery from dementia: An interesting case \\ David Knopman and Janet Jankowiak \\ Neurology 2005;64;E18-E19 \\ DOI 10.1212/WNL.64.4.E18
}

This information is current as of February 22, 2005

\section{Updated Information \&} Services

References

Permissions \& Licensing

Reprints including high resolution figures, can be found at: http://n.neurology.org/content/64/4/E18.full

This article cites 4 articles, 1 of which you can access for free at: http://n.neurology.org/content/64/4/E18.full\#ref-list-1

Information about reproducing this article in parts (figures,tables) or in its entirety can be found online at:

http://www.neurology.org/about/about_the_journal\#permissions

Information about ordering reprints can be found online: http://n.neurology.org/subscribers/advertise

Neurology ${ }^{\circledR}$ is the official journal of the American Academy of Neurology. Published continuously since 1951, it is now a weekly with 48 issues per year. Copyright . All rights reserved. Print ISSN: 0028-3878. Online ISSN: 1526-632X.

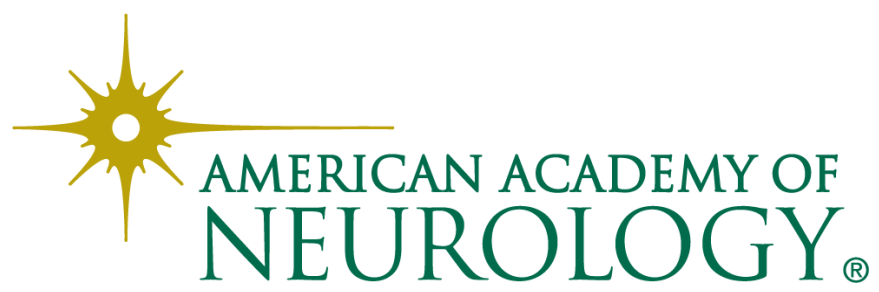

